\section{$\mathbf{R}_{\text {ESEA }} \mathbf{A}_{\text {RT }}^{\mathrm{RCH}}$} A RTICLE

\title{
Effect of herbal growth promoter on dry matter intake and weekly live body weight in Osmanabadi kids solely fed Yeshwant (RBN-9) grass without supplementation of concentrate
}

\author{
P.V. PATIL AND V.M. SALUNKE
}

\begin{abstract}
Osmanabadi kids were randomly selected based on body weight for the present study. The kids were randomly divided in 2 groups containing six kids in each group. One group was the control and other one was the treatment group. The herbal growth promoter (plant extract) was added in ration of treatment group and was not added in control group ration. Weekly feed intake and weekly live body weight were recorded. Results indicated that there is significant increase in dry matter intake and weekly live body weight of Osmanabadi kids due to supplementation of herbal growth promoter.
\end{abstract}

Key words : Herbal growth promoter, Dry matter, Live body weight, Osmanabadi kids

Author for correspondence : P.V. PATIL

Cattle Breeding Farm, College of

Veterinary and Animal Sciences,

Udgir, LATUR (M.S.) INDIA

Email: drprafull1@ @rediffmail.com

'Directorate of Research, College of

Veterinary and Animal Sciences,
How to cite this paper : Patil, P.V. and Salunke, V.M. (2014). Effect of herbal growth promoter on dry matter intake and weekly live body weight in Osmanabadi kids solely fed Yeshwant(RBN-9) grass without supplementation of concentrate. Vet. Sci. Res. J., 5(1\&2) : 27-29.

Paper History : Received : 14.08.2014; Revised : 02.09.2014; Accepted : 17.09.2014 